\title{
Obesity detection rate among primary school students in the People's Republic of China: a meta-analysis
}

This article was published in the following Dove Press journal:

Therapeutics and Clinical Risk Management

10 October 2013

Number of times this article has been viewed

\section{Yue-long Jin* \\ Ling-ling Ding* \\ Ying-shui Yao \\ Xiu-li Song \\ Hui Tang \\ Lian-ping $\mathrm{He}$ \\ Yan Chen}

Faculty of Epidemiology and Statistics, School of Public Health, Wannan Medical College, Anhui, People's Republic of China

*These authors contributed equally to this work
Correspondence: Ying-shui Yao Faculty of Epidemiology and Statistics, School of Public Health, Wannan Medical College, 22 Wenchang West Road, Yijiang District, Wuhu 24I002, Anhui, People's Republic of China

Tel +860553393 265I

Fax +860553393 265I

Email yingshuiyao@163.com
Background: Obesity has become a major public health problem worldwide. The prevalence of obesity is rising alarmingly among children and adolescents in the People's Republic of China, with an estimated 120 million now in the obese range. It is estimated that $8 \%$ of children in the People's Republic of China are obese and 12\% are overweight.

Methods: Eligible papers on the prevalence of obesity among primary school students in the People's Republic of China and published between 2006 and 2011 were retrieved from PubMed and from online Chinese periodicals, ie, the full-text databases of VIP, the Chinese National Knowledge Infrastructure, and Wan Fang. Meta-Analyst software was used to collate and analyze the detection rates cited in the papers retrieved.

Results: After evaluation of the quality of the papers, 25 were finally included, giving a total sample population size for investigation of obesity of 219,763, in which 28,121 cases were detected. Meta-analysis showed that the combined obesity detection rate was $10.4 \%(95 \%$ confidence interval 8.6-12.6) among primary school students in the People's Republic of China, with a higher detection rate in boys $(12.6 \%)$ than in girls $(7.2 \%)$. The prevalence of obesity was higher in the north $(11.8 \%)$ than in the south $(9.5 \%)$, east $(11.6 \%)$, and mid-west $(8.0 \%)$ regions. Obesity defined according to the World Health Organization weight-for-height standard (14.3\%) was higher than that using age-specific and gender-specific cutoff points for body mass index $(9.0 \%)$.

Conclusion: Our meta-analysis found an obesity prevalence rate of $10.4 \%$, which does not seem as high as previous reports of childhood obesity rates in other countries. However, the prevalence of childhood obesity in the People's Republic of China is still worrisome, and is likely to rise even further if we fail to take effective and practical measures now.

Keywords: primary school students, obesity, detection rate, meta-analysis

\section{Introduction}

Obesity is defined as abnormal or excessive accumulation of body fat, and represents a risk to health. In the People's Republic of China, overweight and obesity are significant growing health problems in children, and are threatening their physical and mental health. An indepth understanding of the prevalence of obesity among primary school students in the People's Republic of China could provide an opportunity to focus resources, interventions, and research in directions that would be most beneficial for addressing this problem.

Body mass index (BMI) is acceptable for determining obesity in an individual. It is defined as the individual's body mass divided by the square of his or her height. The World Health Organization (WHO) suggests a BMI $>25.0$ and $<29.9$ as an 
indicator of overweight and $>30$ as obesity. To take international variations into account, the International Life Science Institute proposes the following reference values for BMI in the Chinese population: $18.5-23.9 \mathrm{~kg} / \mathrm{m}^{2}$ for the normal range, $24.0-27.9 \mathrm{~kg} / \mathrm{m}^{2}$ for overweight, and $>28.0 \mathrm{~kg} / \mathrm{m}^{2}$ for obesity. In November 2003, a working group prescribed a nationwide reference when screening for overweight and obesity in school-aged children and adolescents in the People's Republic of China. This reference standard initially provided a quantitative basis for screening of overweight and obesity in Chinese students (herein referred to as age-specific and gender-specific cutoff points for BMI). ${ }^{1}$ The WHO weightfor-height criterion is also widely used in the People's Republic of China, which is according to the standard weight for different heights. It defines weight of $90 \%-110 \%$ standard weight-for-height as normal, $110 \%-120 \%$ as overweight, and $\geq 120 \%$ as obesity (herein referred to as the weight-forheight standard).

Although the authorities have made a commitment to bring obesity under control to $12 \%$ for adults and $8 \%$ for children and teens by 2015 , this is a tough task to achieve. ${ }^{2}$ Analysis of the dynamics of overweight and obesity in different student groups between 1985 and 2000 by $\mathrm{Ji}$ et al suggested that the rapid growth of obesity in the Chinese population should outweigh any concerns about the apparent percentiles of overweight and obesity. ${ }^{3}$ This fact alone should attract the attention of relevant government departments to take effective preventive action against obesity. In this meta-analysis, an attempt was made to investigate the epidemiology of obesity and overweight in school-aged children and adolescents in the People's Republic of China.

\section{Materials and methods Search strategy}

Papers on the topic of obesity published online between 2006 and 2011 were retrieved from PubMed and from the Chinese periodical full-text databases of VIP, Wan Fang, and Chinese National Knowledge Infrastructure using the search terms "obesity/fat", "students", "pupils", "detection rate", and "China" in the Chinese language for the Chinese database and in English for the PubMed database. Eligible full texts were retrieved manually from the above data.

\section{Selection criteria}

Inclusion criteria consisted of: papers published in the literature addressing obesity among primary school students in the People's Republic of China; publication between 2006 and 2011; discussion of the obesity detection rate in Chinese primary school students with clear and reliable statistics; use of obesity criteria, ie, age-specific and gender-specific cutoff points for BMI or the WHO weight-for-height standard; and priority of higher quality papers among the same subjects (when more than one of the same subjects was included in several publications, only the most recent or complete study was included in the meta-analysis). Exclusion criteria included indicators described in articles with less association, data being incomplete, and duplications.

\section{Literature screening and assessment of quality}

Data were extracted from each study according to the selection criteria by two investigators independently, and any disagreements were resolved by a third reviewer. A blinded method was used to ensure quality. The following information was extracted from the literature: first author, year of publication, total sample size, sample size of different gender and area, and the criterion used for obesity. Evaluation of research quality was made according to the criteria proposed by Stroup et $\mathrm{al}^{4}$ for meta-analysis of observational studies.

\section{Statistical analysis}

Meta Analyst Beta 3.13 software (Tufts Medical Center, Boston, MA, USA) was used for meta-analysis of data from the 25 eligible papers. By heterogeneity testing, the randomeffects model was applied for merging sets of data and data analysis. The final data were subdivided into subgroups for statistical analysis and chart description.

\section{Results}

\section{Basic information and assessment of quality}

A total of 1,026 articles were retrieved from the online Chinese periodical full-text VIP (138), Wan Fang (78), and Chinese National Knowledge Infrastructure (142) databases, and from PubMed (668). In total, 964 papers were excluded after preliminary screening. Of these, 332 were review articles. A further 248 papers were investigations of the relationship between obesity and hypertension or diabetes. Another 384 papers reported obesity detection rates in Chinese primary school students, but lacked the necessary data or contained incomplete data, so were excluded. The study with the highest quality was included if multiple publications were based on the same sample. Assessment of quality was made by metaanalysis of observational studies in epidemiology. Thirty-seven 
papers were removed because the judgment standard for obesity was not based on age-specific and gender-specific cutoff points for BMI or the WHO weight-for-height standard. Finally, 25 papers were included, representing 28,121 cases of obesity detected in a total sample size of 219,763 primary school students. Figure 1 shows the process used for literature screening, and basic information on the final papers included is given in Table 1 .

\section{Meta-analysis of obesity detection rates in primary school students in the People's Republic of China}

Heterogeneity testing was carried out for the obesity detection rate, with a result of $I^{2}=0.499$, suggesting that the research results for the 25 papers were heterogeneous.
A random-effects model was introduced to merge the data for meta-analysis. As shown by the forest plots in Figure 2, the pooled prevalence of obesity in the primary school students was $10.4 \%$ (95\% confidence interval [CI] 8.6-12.6).

\section{Subgroup analysis}

Subgroup analysis was based on student gender and distribution by district. After heterogeneity testing, a random-effects model was used for meta-analysis. Table 2 shows the mean prevalence of obesity in primary school students to be $12.6 \%$ (95\% CI 10.0-15.6) for boys and 7.2\% (95\% CI 5.9-8.9) for girls. The prevalence of obesity in northern People's Republic of China was $11.8 \%$ (95\% CI 8.6-15.9), 9.5\% (95\% CI $8.2-11.0)$ in the south, $11.6 \%$ in the eastern areas $(95 \%$ CI 9.3-14.5), and 8.0\% (95\% CI 6.8-9.3) in the mid-west.

Table I Main characteristics of studies showing obesity detection rates among primary school students in the People's Republic of China

\begin{tabular}{|c|c|c|c|c|c|c|c|c|}
\hline \multirow[t]{2}{*}{ Reference } & \multirow[t]{2}{*}{ Year } & \multirow{2}{*}{$\begin{array}{l}\text { Geographic } \\
\text { distribution }\end{array}$} & \multicolumn{3}{|c|}{ Prevalence of obesity (\%) } & \multirow[t]{2}{*}{ Subject } & \multirow{2}{*}{$\begin{array}{l}\text { Age range, } \\
\text { years }\end{array}$} & \multirow[t]{2}{*}{ Criterion } \\
\hline & & & $\begin{array}{l}\text { Total (obesityl } \\
\text { sample size) }\end{array}$ & $\begin{array}{l}\text { Boys (obesityl } \\
\text { sample size) }\end{array}$ & $\begin{array}{l}\text { Girls (obesityl } \\
\text { sample size) }\end{array}$ & & & \\
\hline Chang et $\mathrm{al}^{13}$ & 2006 & Zhangjiakou & $10.15(309 / 3,043)$ & $12.90(205 / 1,587)$ & $7.10(104 / 1,456)$ & Pupil & $7-12$ & BMI \\
\hline Man et $\mathrm{al}^{14}$ & 2006 & Dandong & $9.80(2,97 I / 30,378)$ & $12.10(1,899 / 15,692)$ & $7.30(1,072 / 14,686)$ & Pupil & & $\begin{array}{l}\text { Weight- } \\
\text { for-height }\end{array}$ \\
\hline Liu and $W_{u^{15}}$ & 2006 & Haikou & $13.62(350 / 2,569)$ & I7.08 (248/I,452) & $9.13(102 / 1,117)$ & Pupil & $6-12$ & $\begin{array}{l}\text { Weight- } \\
\text { for-height }\end{array}$ \\
\hline Guo and $\mathrm{Xie}^{16}$ & 2006 & Shenzhen & $7.22(277 / 3,836)$ & $8.99(193 / 2,147)$ & $4.97(84 / 1,689)$ & Pupil & $7-10$ & BMI \\
\hline Mo et $\mathrm{al}^{17}$ & 2008 & Changsha & $7.39(306 / 4,140)$ & $9.37(207 / 2,209)$ & $5.13(99 / 1,931)$ & Pupil & $7-12$ & BMI \\
\hline Lv et $\mathrm{al}^{18}$ & 2008 & Changzhou & $6.43(387 / 6,016)$ & $9.09(284 / 3,123)$ & $3.56(103 / 2,893)$ & Pupil & $7-12$ & BMI \\
\hline Wang et al ${ }^{19}$ & 2009 & Handan & $16.01(2 \mid 6 / 1,349)$ & & & Pupil & $7-12$ & BMI \\
\hline Yu and $\operatorname{Lin}^{20}$ & 2009 & Chengdu & $7.00(421 / 6,047)$ & $8.80(274 / 3,113)$ & $5.00(147 / 2,934)$ & Pupil & $7-12$ & BMI \\
\hline $\mathrm{Li}^{21}$ & 2010 & Jinan & 17.47 (I59/9|0) & $22.27(96 / 431)$ & $13.15(63 / 479)$ & Pupil & $7-12$ & $\mathrm{BMI}$ \\
\hline Sun ${ }^{22}$ & 2010 & Ju'nan & $7.01(215 / 3,066)$ & & & Pupil & $8-12$ & $\begin{array}{l}\text { Weight- } \\
\text { for-height }\end{array}$ \\
\hline Bei et $\mathrm{al}^{23}$ & 2010 & Wuhu & $9.30(964 / 10,381)$ & $10.80(580 / 5,343)$ & $7.60(384 / 5,038)$ & Pupil & & $\mathrm{BMI}$ \\
\hline Huang et $\mathrm{al}^{24}$ & 2010 & Xiamen & $9.42(4,853 / 51,516)$ & $12.35(3,503 / 28,375)$ & $5.83(I, 350 / 23,14 I)$ & Pupil & $7-11$ & BMI \\
\hline Hu et $\mathrm{al}^{25}$ & 2010 & Zhenjiang & $8.70(144 / I, 655)$ & $13.40(128 / 952)$ & $7.00(49 / 703)$ & Pupil & & BMI \\
\hline Liu et $\mathrm{al}^{26}$ & 2010 & Linghai & $9.60(172 / 1,798)$ & $12.80(121 / 946)$ & $6.00(5 \mathrm{I} / 852)$ & Pupil & & $\mathrm{BMI}$ \\
\hline $\begin{array}{l}\text { Zhang and } \\
\text { Zhao }^{27}\end{array}$ & 2010 & Xinyang & $6.17(111 / 1,800)$ & $7.50(69 / 920)$ & $4.77(42 / 880)$ & Pupil & $7-12$ & BMI \\
\hline $\begin{array}{l}\text { Zeng and } \\
\text { Chen }^{6}\end{array}$ & 2010 & Yangchun & $4.19(50 / 1,219)$ & $5.91(40 / 677)$ & $1.85(10 / 542)$ & Pupil & & BMI \\
\hline Zhuang $^{28}$ & 2011 & Chaozhou & $10.26(4 \mid 7 / 4,064)$ & $13.58(290 / 2,136)$ & $6.59(127 / 1,928)$ & Pupil & $7-12$ & $\mathrm{BMI}$ \\
\hline $\begin{array}{l}\text { Jiang and } \\
\text { Zhao }{ }^{29}\end{array}$ & 2011 & Ji'an & II.20 (319/2,836) & I4.50 (204/I,405) & $8.00(115 / 1,431)$ & Pupil & $7-12$ & $\begin{array}{l}\text { Weight- } \\
\text { for-height }\end{array}$ \\
\hline Zhang $^{30}$ & 2011 & Guangzhou & I4.54 (I54/I,059) & $16.55(94 / 568)$ & $12.22(60 / 491)$ & Pupil & $6-12$ & $\mathrm{BMI}$ \\
\hline Ren et $\mathrm{al}^{7}$ & 2011 & Langfang & $25.10(690 / 2,749)$ & $31.10(440 / I, 415)$ & I8.74 (250/I,334) & Pupil & & $\begin{array}{l}\text { Weight- } \\
\text { for-height }\end{array}$ \\
\hline Fu et $\mathrm{al}^{3 \mathrm{I}}$ & 2011 & Shanghai & $22.64(40 I / I, 77 I)$ & & & Pupil & $7-12$ & $\begin{array}{l}\text { Weight- } \\
\text { for-height }\end{array}$ \\
\hline Huang et $\mathrm{al}^{32}$ & 2011 & Beijing & $21.00(12,124 / 57,97 \mid)$ & $28.00(7,795 / 27,863)$ & $14.40(4,329 / 30,108)$ & Pupil & & $\begin{array}{l}\text { Weight- } \\
\text { for-height }\end{array}$ \\
\hline Chou et $\mathrm{al}^{33}$ & 2011 & Kunshan & I2.25 (I,427/II,646) & $14.86(990 / 6,661)$ & $8.76(437 / 4,985)$ & Pupil & & $\begin{array}{l}\text { Weight- } \\
\text { for-height }\end{array}$ \\
\hline Liu et $\mathrm{al}^{34}$ & 2011 & Hebi & $7.41(139 / 1,876)$ & $5.42(52 / 959)$ & 9.49 (87/917) & Pupil & $7-12$ & $\mathrm{BMI}$ \\
\hline Lai et $\mathrm{al}^{35}$ & 2011 & Shenzhen & $8.98(545 / 6,068)$ & $10.65(335 / 3,147)$ & $7.19(210 / 2,921)$ & Pupil & $7-12$ & BMI \\
\hline
\end{tabular}

Note: BMI here refers specifically to age-specific and gender-specific cutoff points for body mass index. 


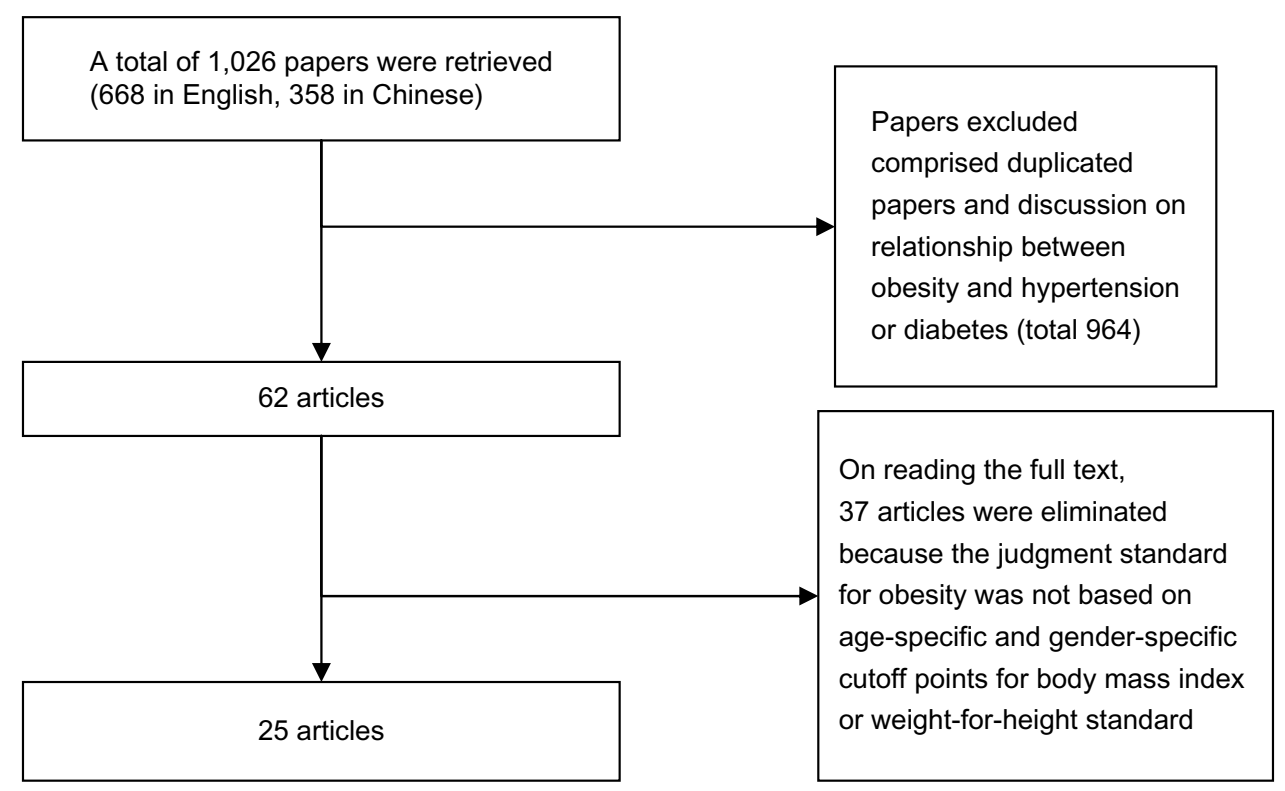

Figure I Flow chart for literature screening.

The obesity detection rate was $9.0 \%(95 \%$ CI $8.0-10.0)$ using the age-specific and gender-specific cutoff points for BMI criterion and 14.3\% (95 CI 10.4-19.4) using the WHO weight-for-height standard.

\section{Publication bias}

Publication bias refers to the tendency of a study to produce apparently statistically significant results leading investigators to submit manuscripts and for reviewers and editors to accept them. Although this is a potential threat in meta-analysis, it may be avoided by using funnel plots, ${ }^{5}$ and we used these to test for possible bias in our literature selection. Verification by funnel plot (Figure 3) showed that the literature included were in better symmetry with the narrow top and wide bottom, suggesting a low likelihood of publication bias with regard to detection of obesity rates in primary school students in the People's Republic of China.

\section{Discussion}

As shown in Table 1, obesity detection rates among primary school students in the People's Republic of China varied widely from $4.1 \%{ }^{6}$ to $25.1 \%$. This broad variation may be associated with differences in sample size, an imbalance in regional economic development in the People's Republic of China, and/or year of publication. Nevertheless, our meta-analysis competently represents the current picture of obesity prevalence among primary school students in the People's Republic of China.

Our findings on the basis of the literature suggest that obesity disproportionately affects certain groups of children, with higher detection rates in boys than in girls. A possible explanation for these results may lie in: the physiologic differences between boys and girls; the traditional Chinese thinking that male gender is the strongest within the family, as a consequence of diverse food quality treatment for boys and girls and the irrational perception that slender figures are more beautiful for girls; and the conventional stereotype on the part of parents who value boys over girls such that the food intake of boys should be greater than that of girls, thus resulting in a potentially higher prevalence of obesity in male students. A higher prevalence of obesity was seen in the northern and eastern areas of the People's Republic of China as compared with the south and mid-west. A likely explanation for this difference is the different eating habits between the northern and southern areas. In addition, the highly developed economy in eastern People's Republic of China has led to urban children from wealthy families being transported in more modern vehicles and being more sedentary, leading to less daily physical activity and decreased daily energy expenditure but more ready accumulation of body fat; in contrast, obesity is less likely in western People's Republic of China, where the economy is relatively underdeveloped, and growth deficiencies due to poor nutrition occur more often than obesity in children. This is further demonstrated by data showing that overweight or obesity in adolescents from affluent families was 1.6 times higher than in children from less wealthy families. ${ }^{8}$ In contrast, the rapidly increasing problem of obesity in children in the UK is concentrated in the lower socioeconomic classes. ${ }^{9}$ A possible interpretation of this difference between the western world and the People's Republic of China is that families of higher socioeconomic status in industrialized 


\section{Proportion: 95\% confidence interval}

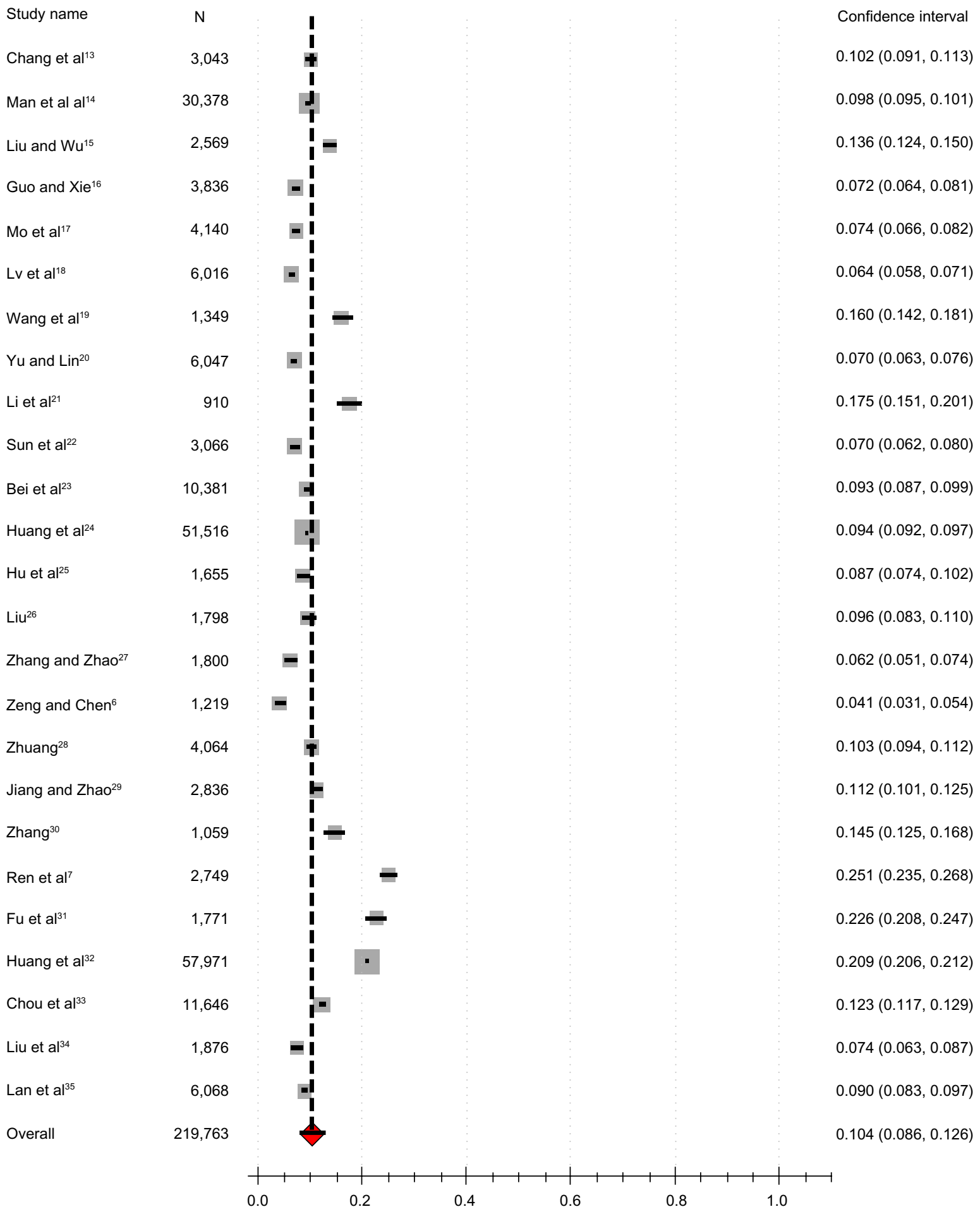

Figure 2 Forest plot for obesity prevalence and confidence intervals for obesity in each study and the overall prevalence in the meta-analysis.

developed nations have access to more healthy food and have better dietary habits. Our findings show that the obesity detection rate using the $\mathrm{WHO}$ weight-for-height criterion was higher than that using the criterion of age-specific and gender-specific cutoff points for BMI. Both these criteria are widely used in the People's Republic of China for detecting obesity in primary school students, and further study is needed to determine which method is the most useful.

In 2010, the Centers for Disease Control and Prevention reported that $17 \%$ of US children were obese. ${ }^{10}$ In the same 
Table 2 Mean prevalence of obesity among primary school students in different subgroups

\begin{tabular}{|c|c|c|c|c|c|c|c|c|}
\hline & \multicolumn{2}{|l|}{ Gender } & \multicolumn{4}{|c|}{ District distribution } & \multicolumn{2}{|c|}{ Criterion } \\
\hline & Male & Female & South & North & East & Mid-west & BMI & Weight-for-height \\
\hline Study number & 22 & 22 & 14 & 11 & 19 & 6 & 17 & 8 \\
\hline Prevalence (\%) & 12.6 & 7.2 & 9.5 & 11.8 & 11.6 & 8.0 & 9.0 & 14.3 \\
\hline $95 \% \mathrm{Cl}(\%)$ & $10.0-15.6$ & $5.9-8.9$ & $8.2-11.0$ & $8.6-15.9$ & $9.3-14.5$ & $6.8-9.3$ & $8.0-10.0$ & $10.4-19.4$ \\
\hline Heterogeneity $\left(I^{2}\right)$ & 0.499 & 0.497 & 0.495 & 0.499 & 0.499 & 0.482 & 0.489 & 0.499 \\
\hline
\end{tabular}

Notes: BMI here specifically refers to age-specific and gender-specific cutoff points for body mass index. North and South are divided by Qinling Mountains-Huaihe River Line. East and mid-west are divided by economic development level.

Abbreviations: $\mathrm{BMI}$, body mass index; $\mathrm{Cl}$, confidence interval.

year, $30 \%$ of UK children were reported to be obese. The cultural habits relating to food in the US and UK may be the most significant factor in these obesity rates. Many of the favorite foods in both countries, including hamburgers, French fries, and doughnuts, are high in carbohydrate content. Children frequently demand that these foods be included in their diet. In Singapore, the percentage of obese school children remained at about 12\% from 2007 to 2010. Further, official statistics from the Food and Health Bureau of the Government of Hong Kong Special Administrative Region, People's Republic of China, show that the prevalence of obesity is as high as $21.3 \%$. Although the mean prevalence rate in our meta-analysis was only $10.4 \%$, ie, lower than the above data, the prevalence of obesity in the People's Republic of China is still worrisome, in that if we fail to implement effective preventive and control measures now, the situation will get worse. As in adults, obesity in childhood causes hypertension, type 2 diabetes, hyperinsulinemia, and Endocrine-Neurogenic Tumor. ${ }^{11}$ Apart from that, obesity in childhood tends to be a risk factor for mental growth in childhood and even represents social dysfunction when children grow up. Obese children often feel upset when they are too big to fit into beautiful dresses and classmates also make fun of their body size. Given the rising childhood obesity rates in the People's Republic of China, our education departments and health authorities should jointly implement effective and practical measures, such as health education and regular physical examinations, to bring childhood obesity under control. In addition, parents

\section{Funnel plot}

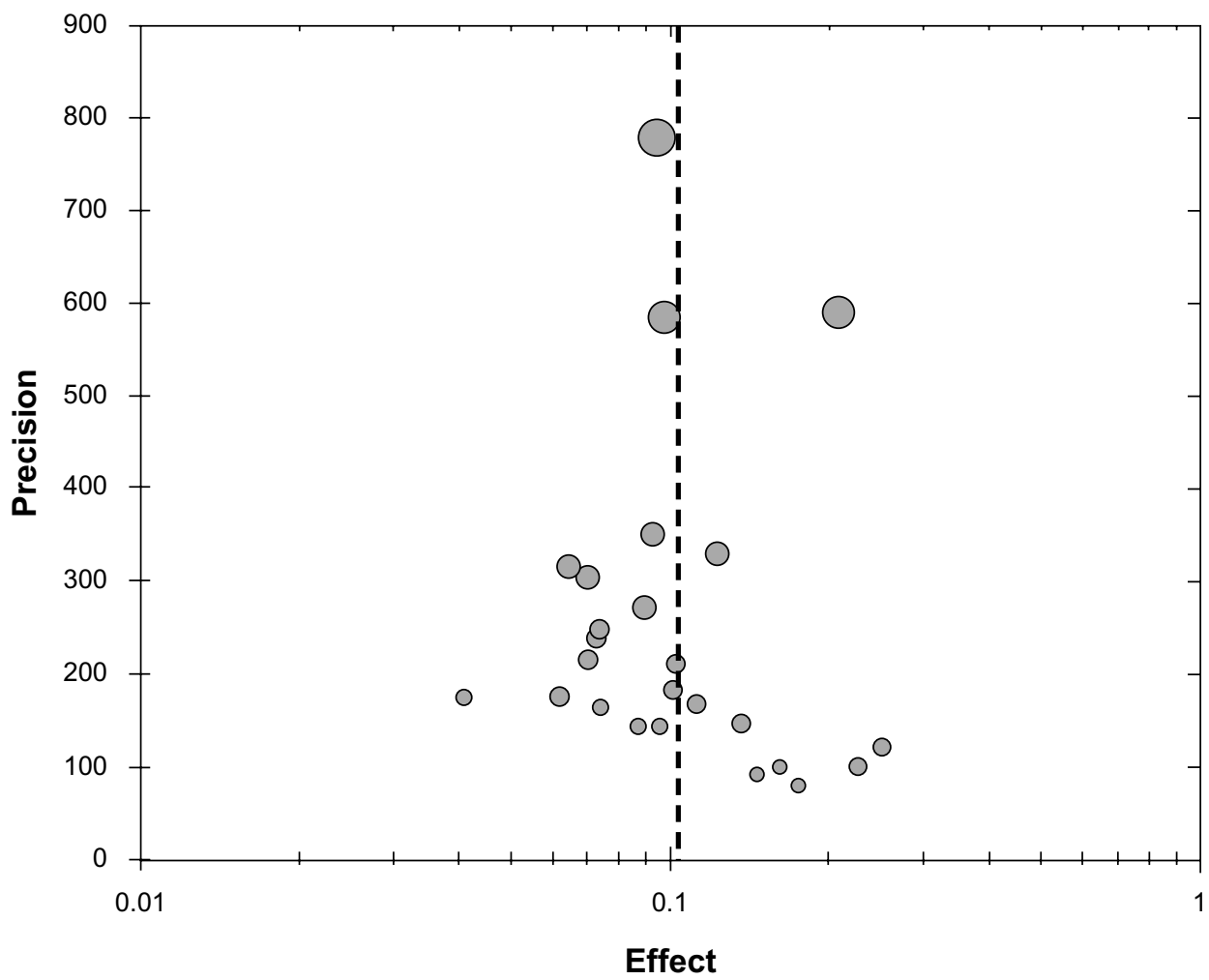

Figure 3 Funnel plot for overall prevalence in the meta-analysis. 
should be educated about the importance of healthy eating, and students should be encouraged to take more exercise and develop good lifestyle habits. ${ }^{12}$ Our recommendations for the future include: improvement of awareness about the hazards of obesity; earlier implementation of preventive measures; development of reasonable eating habits including a balanced diet and less intake of foods with high calories; more physical exercise, such as running, swimming, or other physical activity; development of healthy lifestyle behaviors, such as keeping to a regular daily timetable and a regular diet; and keeping an optimistic attitude and a peaceful mood.

\section{Acknowledgment}

This study was supported by the National High-tech R\&D Program of China (2006AA02Z427).

\section{Author contributions}

The work presented here was carried out in collaboration between all authors. YJ, LD and YY defined the research theme. YJ and LD designed methods and collected data, analyzed the data and interpreted the results. LH, YC, XS, and HT co-designed the methods and conducted the data analysis, and co-worked on associated data collection and their interpretation. YY co-designed methods, discussed analyses, interpretation, and presentation. All authors were involved in drafting the article or revising it critically for important intellectual content. All authors have approved the manuscript.

\section{Disclosure}

The authors report no conflicts of interest in this work.

\section{References}

1. Chinese Obesity Group, International Life Science Institute. BMI screening standard of overweight and obesity among Chinese students. Conference on obesity among children and teenagers in China, 2003:1-26. Beijing, People's Republic of China.

2. Association for Chinese Students' Nutrition and Health. Report of Chinese children and teenagers' nutrition and health in 2009: Concerned about childhood obesity, away from chronic diseases. Beijing, People's Republic of China: Population Press; 2009.

3. Ji CY, Sun JL. [Analyses of the epidemiologicalstatus of overweight and obesity in Chinese students and the prevalence changes in recent 15 years.] Beijing Da Xue Xue Bao. 2004;36(2):194-197. Chinese.

4. Stroup DF, Berlin JA, Morton SC, et al. Meta-analysis of observational studies in epidemiology: a proposal for reporting. Meta-analysis Of Observational Studies in Epidemiology (MOOSE) group. JAMA. 2000;283(15):2008-2012.

5. Wang Z, Zhang YH, Xu QQ. Several methods of published bias assessment. Chinese Journal of Health Statistics. 2009;26(5):539-541.

6. Zeng YH, Chen HZ. Prevalence of overweight and obesity and its influencing factors among primary school students in Yangchun. Chin J Sch Health. 2010;31(7):835-836.

7. Ren HY, Liu WL, Yan ZL, et al. Analysis of the prevalence status and influencing factors of obesity in students. Hebei Medical Journal. 2011;3(18):2839-2840.
8. Wang YP. Obesity among Chinese college students and health education measures. Medical Information. 2011;9:4938-4939.

9. Xu F, Yin XM, Zhang M, Leslie E, Ware R, Owen N. Family average income and body mass index above the healthy weight range among urban and rural residents in regional Mainland China. Public Health Nutr. 2005;8(8):47-51.

10. Centers for Disease Control/National Center for Health Statistics. National Obesity Trends; 2010. Available from: http://www.cdc.gov/ obesity/data/adult.html. Accessed September 3, 2013.

11. He WX. Correlative disease of obesity among childhood. Journal of Applied Clinical. 2004;19(1):77-78.

12. Lagerros YT, Rossner S. Managing obesity - from childhood and onwards. Int J Pediatr Obes. 2011;6 Suppl 1:74-78.

13. Chang XT, Dong MG, Wu JL, et al. Analysis on the prevalence of obesity among pupils in Zhangjiakou. Chin J Sch Health. 2006;27(10): 836-837.

14. Man YX, Zheng LL, Guo JY, et al. Analysis on the prevalence of overweight and obesity among pupils in Dandong. Chin J Sch Health. 2006;27(6):515.

15. Liu L, Wu HQ. Analysis on the prevalence of simple obesity among pupils in Haikou. Chin J Sch Health. 2006;27(6):519.

16. Guo SY, Xie YN. Survey of status of fatness in primary school pupils Longgang District, Shenzhen City and preventive measures. China Tropical Medicine. 2006;6(5):892-893.

17. Mo J, Wu J, Huang CW, et al. The study on overweight and obesity among primary school pupils in Kaifu District in Changsha. Progress in Modern Biomedicine. 2008;8(6):1117-1118.

18. Lv JZ, Hua F, Huang XY, et al. Analysis on the prevalence of obesity among pupils in Changzhou. Chin J Sch Health. 2008;29(1):36.

19. Wang HH, Pan LX, Shao R, et al. Investigation of obesity among pupils in Handan. Journal of Handan College. 2009;19(1):117-118.

20. Yu T, Lin JQ. Analysis of the prevalence status of overweight and obesity in students in Chengdu. Chinese Journal of Practical Pediatrics. 2009;24(7):556-558.

21. Li L, Xu GF, XY, et al. Analyzing the status of pupils' obesity in Jinan and its influencing factors. Chinese Health Service Management. 2010;11(269):773-777.

22. Sun QY. Analysis on the prevalence of simple obesity among 3066 pupils in Junan. Journal of Community Medicine. 2010; 8(18):64.

23. Bei YJ, Zuo XR, Guo RF. Present condition and causes of obesity among primary school students in Wuhu and corresponding interventions reflections on obesity of students from 27 primary school in Wuhu. Journal of Shandong Institute of Physical Education and Sports. 2010;26(9):64-66.

24. Huang PZ, Bai H, Chen JF. Survey of status of fatness among primary school pupils in Xiamen and preventive measures. Journal of Public Health and Preventative Medicine. 2010;21(2):87-88.

25. Hu YR, Ding F, Zhou Y, et al. Prevalence of obesity and its influence factors among primary school students in Runzhou district of Zhenjiang. Chin J Sch Health. 2010;31(1):23-24.

26. Liu XH, Zhu L, Shi XZ, et al. Linghai pupils overweight and obese survey. Journal of Shenyang Medical College. 2010;12(2): $103-105$.

27. Zhang H, Zhao YX. Analysis on simple obesity and its effect factors in primary school students in Xinyang. Maternal and Child Health Care of China. 2010;25(24):3464-3466.

28. Zhuang J. Analysis on obesity among primary school students in Chaozhou. South China Journal of Preventative Medicine. 2011;37(6): 50-55.

29. Jiang YJ, Zhao H. Analysis influencing factors among primary school students obesity in Ji' an. Chinese Journal of Public Health Engineering. 2011;10(5):433-434.

30. Zhang Z. Investigation on obesity among 6-12 primary school students. JCM. 2011;9(6):16-17.

31. Fu JZ, Fan HE, Si M, et al. Prevalence of overweight and obesity among 7-12-year-old students in one center districts in Shanghai. Chin J Sch Health. 2011;32(11):1341-1343. 
32. Huang JH, Huang H, Ma LR, et al. Prevalence of overweight among students in Dongcheng district. Capital Journal of Public Health. 2011;5(4):173-175.

33. Chou JR, Zhang J, Bao XP, et al. Health status of primary and secondary school students in the development zone of Kunshan. Medical Journal of Communications. 2011;25(3):261-263.
34. Liu ZY, Sun JF, Chen SY. Analysis of the prevalence status and influencing factors of simple obesity among pupils in Hebi. Guangxi Medical Journal. 2011;33(5):615-617.

35. Lai FQ, Ou ZM, Ouyang XH, et al. Investigation on overweight and obesity of middle and primary school students in the Longgang district of Shenzhen. J Trop Med. 2011;11(7):799-801.

\section{Publish your work in this journal}

Therapeutics and Clinical Risk Management is an international, peerreviewed journal of clinical therapeutics and risk management, focusing on concise rapid reporting of clinical studies in all therapeutic areas, outcomes, safety, and programs for the effective, safe, and sustained use of medicines. This journal is indexed on PubMed Central, CAS,
EMBase, Scopus and the Elsevier Bibliographic databases. The manuscript management system is completely online and includes a very quick and fair peer-review system, which is all easy to use. Visit http://www.dovepress.com/testimonials.php to read real quotes from published authors.

Submit your manuscript here: http://www.dovepress.com/therapeutics-and-clinical-risk-management-journal 